\title{
PASIREOTIDE- THE LAST TREATMENT OPTION IN CUSHING'S DISEASE - CASE REPORT
}

Corina Galesanu1,2 A. Condrea1, D.Niculescu ${ }^{3}$, A. Florescu ${ }^{1}$, Liliana Moisii ${ }^{4}$, V. Ciubotaru 5

1. University of Medicine and Pharmacy "Gr. T Popa "Iasi, Romania

2.Endocrinology, 3. Surgery, 4. Radiology, "Sf. Spiridon" Emergency Clinical Hospital Iasi, Romania 5.Neurosargery Hospital "Bagdasar-Arseni" Bucuresti-Romania

\section{INTRODUCTION}

Cushing's syndrome, first described by Harvey Cushing in 1912 represents the clinical expression of chronic glucorticoid excess. The most common causes of Cushing's syndrome are: ACTH secreting tumors of the pituitary gland( Cushing's Disease), cortisol secreting tumors of the adrenal glands( mostly benign but also malignant), non pituitary ACTH secreting tumors (in the lungs or pancreas-ectopic ACTH secretion) and iatrogenic Cushing's syndrome in glucorticoid treatment.

\section{CLINICAL EXAM}

$\mathrm{H}=172 \mathrm{~cm} ; \mathrm{W}=82 \mathrm{~kg} ; \mathrm{BMI}=27,7 \mathrm{~kg} / \mathrm{m} 2$

$B P=130 / 80 \mathrm{~mm} \mathrm{Hg}, P=70 \mathrm{bpm}$

Red round face, strech marks on the abdomen and thighs, upper body

obesity with thin arms and legs

\section{Case report}

We present the case of a 40 year old man diagnosed in 2005 with Cushing's Disease for which a left adrenalectomy was performed (pathology report: diffuse and nodular adenomatous hyperplasia). In january $\mathbf{2 0 0 6}$ due to the persistence of hypercortisolism and the revealing of diffuse adenomatous hyperplasia on the right adrenal gland $(49 / 29 \mathrm{~mm})$, surgery was performed on this location also. Post op evolution was not good, the signs and symptoms of Cushing's Disease persisted, the urinary cortisol levels were very high and because of that Ketoconazol treatment was initiated for 3 months after which another surgery was performed on the left adrenal gland ( CT showing a 1,5 cm nodule). Until 2008 the plasmatic and urinary cortisol levels remain at the upper limit under Ketoconazol therapy, then due to high ACTH levels and the finding of a microadenoma of the pituitary gland, transsphenoidal surgery is performed which proves to be inefficient. The ACTH values remain high and another surgery is required which manages to normalize the ACTH and cortisol levels until 2012 when due to increased ACTH cyproheptadine treatment was initiated ( $6 / 4 \mathrm{cp} /$ daily).

\begin{tabular}{|c|}
\hline /الו \\
\hline
\end{tabular}

\section{IMAGISTIC TESTS}

Thyroid ultrasound- VT=10 $\mathrm{cm} 3$, normal echostructure.

Abdomen ultrasound-Adrenal glands surgically removed, gall bladder-

normal echostructure no stones or other abnormalities were detected.

Cardiac ultrasound-normal systolic and diastolic function

Head MRI -shows a microadenoma of the pituitary gland $(6 / 4 / 6 \mathrm{~mm})$
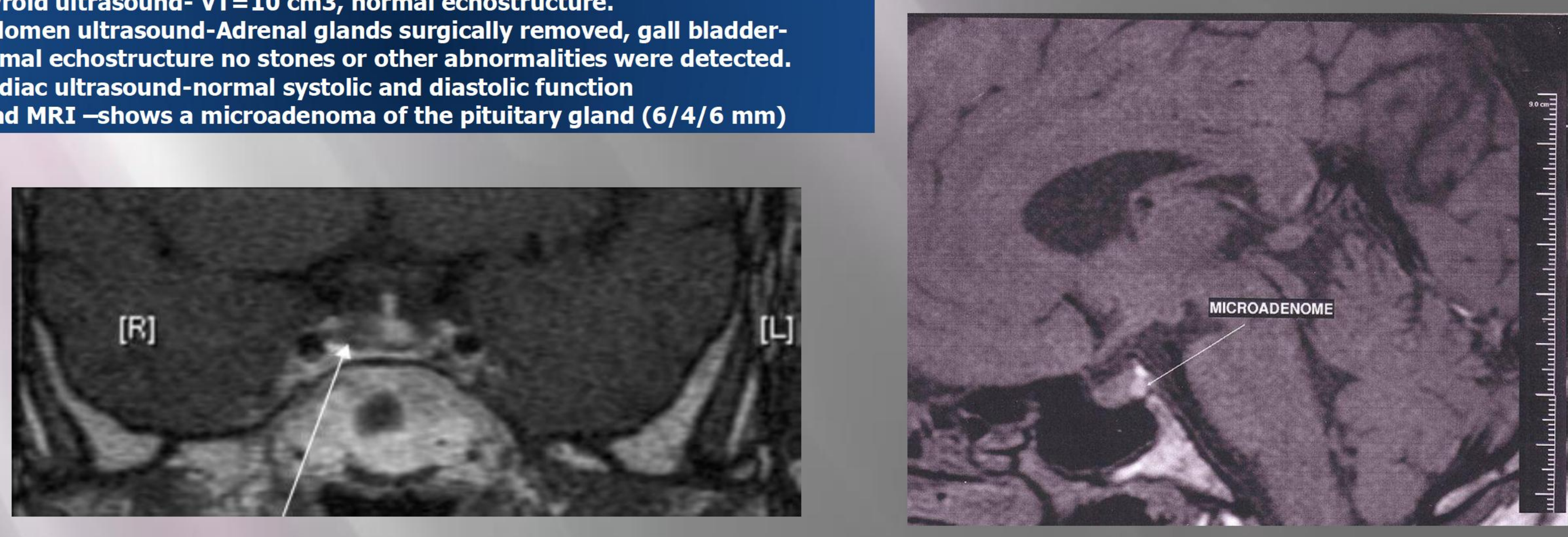

Due to high levels of ACTH and urinary cortisol associated with a typical cushing aspect and the RMI showing the microadenoma we decide to start the treatment with Pasireotide ( $0,3 \mathrm{mg} \times 2 /$ daily) with a 2 month follow up ( in october).

\begin{tabular}{|c|c|c|}
\hline Follow up & UFC & ACTH \\
\hline 20.10 .2014 & $\begin{array}{c}65,97 \mathrm{nmol} / 24 \mathrm{~h} \\
(100-379)\end{array}$ & $51,3 \mathrm{pg} / \mathrm{ml}(0-46)$ \\
\hline 20.01 .2015 & $145 \mathrm{ug} .24 \mathrm{~h}(9,5-148)$ & $112 \mathrm{pg} / \mathrm{ml}(0-46)$ \\
\hline
\end{tabular}

\section{CONCLUSIONS}

In our patient's case Pasireotide was the last and only treatment option left because all of the other treatment measures ( medical and surgical) proved to be inefficient. The response to the treatment was very good , the urinary cortisol levels which were very high normalized after only 2 months and the ACTH values lowered. Pasireotide proved to be very effective in controlling Cushing's Disease on a patient whose pituitary surgery has not been curative. 